\title{
Tear lipid layer deficiency associated with incomplete blinking: A case report
}

Motoko Kawashima ${ }^{1,2^{*}}$ and Kazuo Tsubota ${ }^{2,3}$

\begin{abstract}
Background: Meibomian gland obstruction induces hyposecretion of tear film lipids, which results in lipid layer deficiency and evaporative dry eye. Unfortunately, the importance of blinking in meibomian gland dysfunction has been largely overlooked, and it is not known whether incomplete blinking causes tear lipid deficiency, even in the unobstructed meibomian glands.

Case presentation: A 38-year-old woman suffering from foreign body sensations in her eyes was examined. The cornea was clear and tear secretion was normal. Lid margin abnormalities were not observed and the meibum was clear. However, the lipid layer was very thin, and the patient was given a diagnosis of incomplete blinking. The patient was made aware of her condition and asked to blink consciously and completely. After that, an immediate increase in lipid flow was observed.
\end{abstract}

Conclusion: Tear lipid layer deficiency can occur with incomplete blinking, even though meibomian gland structures are intact. This case highlights the importance of complete blinking.

Keywords: Lipid layer, Blink, Meibomian gland

\section{Background}

Dry eye disease (DED) is a common, yet complex condition that is most often caused by meibomian gland dysfunction (MGD) [1]. Meibomian gland obstruction and gland drop out contribute hyposecretion of tear film lipids, which results in lipid layer deficiency and evaporative DED [1,2]. Recently developed noncontact meibography allows physicians to clearly and noninvasively observe meibomian gland morphology [3]. Subjective ocular symptoms, lid margin abnormalities by slit lamp examination, diagnostic meibomian gland expression and meibomian gland structure observations by meibography are necessary for diagnosing obstructive MGD [3]. Unfortunately, the importance of blinking in MGD has been largely overlooked, and little has been reported on tear lipid deficiency caused by incomplete blinking even in the unobstructed meibomian glands.

\footnotetext{
* Correspondence: motoko-k@a3.keio.jp

'MGD Clinic, Keio University School of Medicine, Tokyo, Japan ${ }^{2}$ Department of Ophthalmology, Keio University School of Medicine, 35 Shinanomachi, Shinjuku, Tokyo 160-8582, Japan

Full list of author information is available at the end of the article
}

\section{Case presentation}

A 38-year-old woman with a 15-year history of disposable contact lens (CL) use presented to our clinic, complaining of a foreign body sensation in her eyes. She also had $>8$ hours/day of visual display terminal (VDT) exposure. Her symptom score on the Standard Patient Evaluation for Eye Dryness questionnaire (score range $0-28$; for those with the score of $\geqq 6$, further DED examinations are recommended.) was 8 . On slit lamp examination performed 4 hours after CL removal, the cornea was clear and no fluorescein staining was observed. Tear film break-up time was 4 seconds in the right eye and tear secretion volume measured by the Schirmer I test was $25 \mathrm{~mm}$. Lid margin abnormalities, such as irregular lid margin, vascular engorgement, plugged meibomian gland orifices, and mucocutaneous junction displacement, were not observed. Clear meibum was easily expressed and noncontact meibography showed no loss of meibomian glands in either the upper or lower lids (Figure 1). Measurements and observations in the left eye were similar to those of the right eye. Neither eye met the diagnostic criteria for DED or MGD.

The LipiView Ocular Surface Interferometer (TearScience, Inc., Morrisville, North Carolina) is a non-invasive instru-

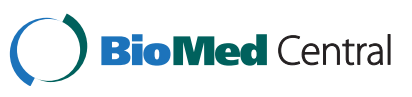




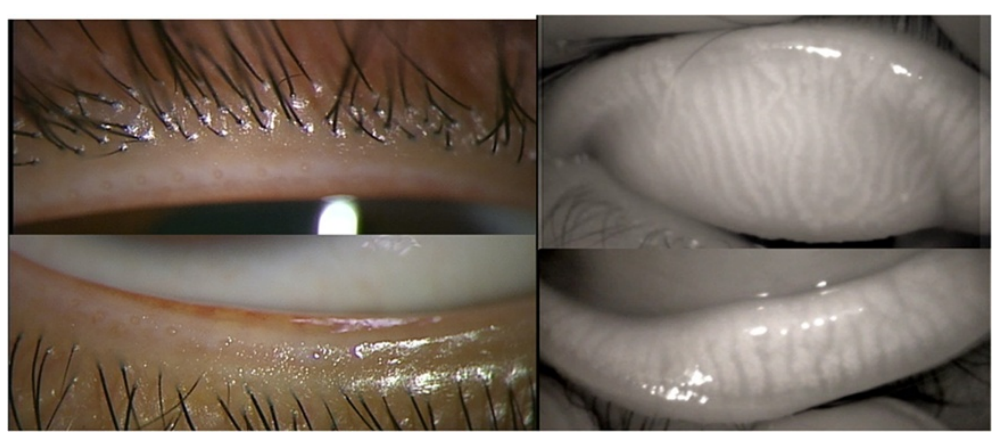

Figure 1 Normal upper and lower lid margin and meibography findings. Normal meibomian gland structures are visible.

ment that captures live digital images of the tear film, measures its lipid content, and assesses blink dynamics. The LipiView evaluates lipid layer thickness through an Interference Color Unit score (normal average ICU score is 275 ). Surprisingly, even without CL use, this patient's average Interference Color Unit score was 24, indicative of a very thin lipid layer.

The LipiView examination also revealed that the patient's incomplete blink rate was abnormally high (Figure 2A). The patient was made aware of this anomaly and its significance and was asked to blink consciously and completely. LipiView examination was immediately performed again and a significant increase in lipid flow was observed (Figure 2B).

\section{Discussion}

This case suggests that tear lipid layer deficiency can occur with incomplete blinking, even though meibomian gland structures are intact. We agree with previous reports that suggest that blinking efficiency affects the ocular surface health $[4,5]$. An incomplete blink leads to inadequate lipid distribution (thin lipid layer) as well as consequent exposure over the inferior ocular surface, which may increase evaporation. In agreement with
A

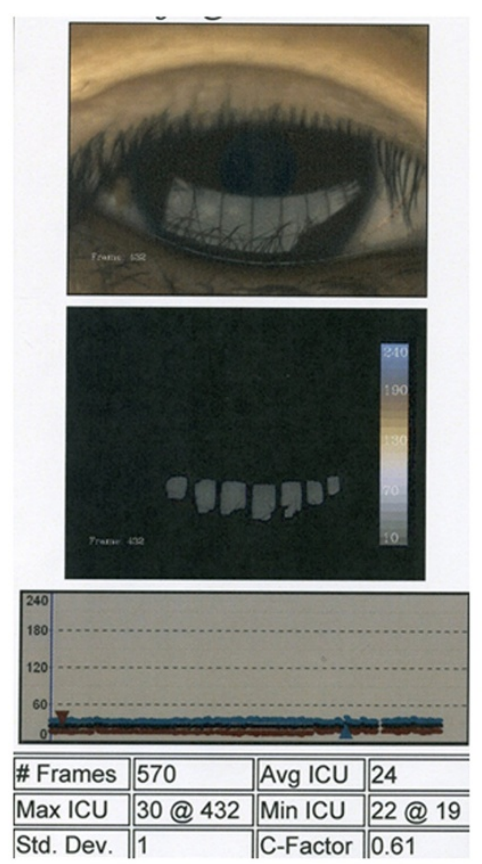

B
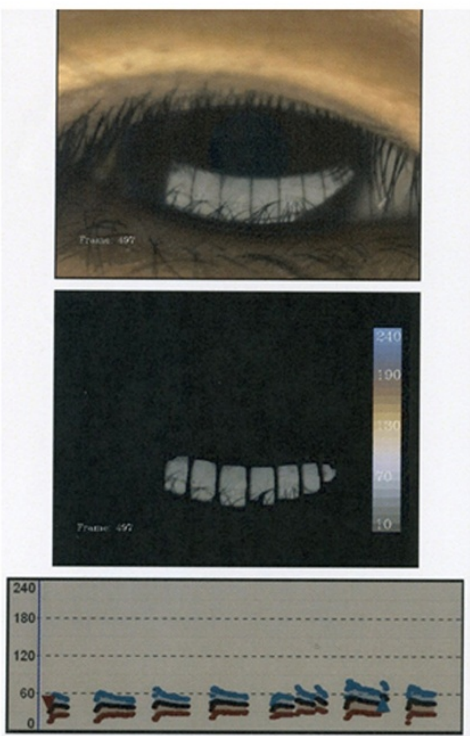

\begin{tabular}{|l|l||l||l||}
\hline \hline \# Frames & 570 & Avg ICU & 43 \\
\hline \hline Max ICU & 57 @ 497 & Min ICU & 29 @ 17 \\
\hline \hline Std. Dev. & 5 & C-Factor & 0.89 \\
\hline
\end{tabular}

Figure 2 LipiViewresults before (A) and after (B) complete blinking from a 38-year old woman, complaining of foreign body sensation. Average Interference Color Unit (ICU) score was 24 before blinking and 43 immediately after blinking (normal average ICU score is $\geq 75$ ). 
Korb et al., [6] who reported that forceful blinking leads to significant increases in lipid layer thickness, this case demonstrates that conscious and complete blinking can also improve meibomian gland lipid flow. It also suggests that proper blinking is important in lipid layer maintenance through augmentation of meibomian gland lipid expression and lipid spreading across the tear film. Further, McMonnies CW suggested that lubricant eye drop instillation combined with blink efficiency exercises may increase the therapeutic benefit to ocular surface epithelium with the potential to improve tear distribution so that DED symptoms are alleviated and/ or prevented [7].

During work at a VDT, both the blink rate and the number of complete blinks are decreased [8]. The recent marked increase in VDT exposure has also resulted in a marked increase in the number of DED patients. Furthermore, long-term CL use weakens the Muller's muscle, which can lead to blink deficiency [9]. Therefore, more attention should be more attention should be given to blinking status, even in patients with no clinical findings for MGD (e.g., meibomian gland dropout, meibomian orifice obstructions). Although MGD mostly affects older people, lipid deficiency can occur in younger patients. In fact, lipid deficiency with no meibomian gland obstruction is estimated to be widespread in younger patients, especially those using $\mathrm{CL}$ and having a high VDT exposure $[10,11]$. In addition to current treatments, improving the blink quality and quantity may be useful in treating DED.

\section{Conclusions}

Tear lipid layer deficiency can occur with incomplete blinking, even though meibomian gland structures are intact. This case highlights the importance of complete blinking.

\section{Consent}

Written informed consent was obtained from the patient for publication of this case report and any accompanying images. A copy of the written consent is available for review by the Editor of this journal.

\footnotetext{
Abbreviations

VDT: Visual display terminal; MGD: Meibomian gland dysfunction; DED: Dry eye disease; CL: Contact lens; ICU: Interference color unit.
}

\section{Competing interests}

The authors have declared that no competing interests exist.

\section{Authors' contributions}

MK conceived of the study, performed the examination and drafted the manuscript. KT helped to draft the manuscript. Both authors read and approved the final manuscript.

\section{Acknowledgements}

We thank Mr. Tomoo Obayashi, Dr. Takeshi Ide, Dr. Sachiko Inoue, and Dr. Reiko Arita for technical assistance and advice.

\section{Financial support}

No financial support was received for this submission.

\section{Author details}

${ }^{1} M G D$ Clinic, Keio University School of Medicine, Tokyo, Japan. ${ }^{2}$ Department of Ophthalmology, Keio University School of Medicine, 35 Shinanomachi, Shinjuku, Tokyo 160-8582, Japan. ${ }^{3}$ Minamiaoyama Eye Clinic, Tokyo, Japan.

Received: 4 November 2012 Accepted: 15 July 2013

Published: 16 July 2013

\section{References}

1. Lemp MA, Crews LA, Bron AJ, Foulks GN, Sullivan BD: Distribution of aqueous-deficient and evaporative dry eye in a clinic-based patient cohort: a retrospective study. Cornea 2012, 31(5):472-478.

2. Tomlinson A, Bron AJ, Korb DR, Amano S, Paugh JR, Pearce El, Yee R, Yokoi $\mathrm{N}$, Arita R, Dogru M: The international workshop on meibomian gland dysfunction: report of the diagnosis subcommittee. Invest Ophthalmol Vis Sci 2011, 52(4):2006-2049.

3. Arita R, Itoh K, Maeda S, Maeda K, Furuta A, Fukuoka S, Tomidokoro A, Amano S: Proposed diagnostic criteria for obstructive meibomian gland dysfunction. Ophthalmology 2009, 116(11):2058-2063. e2051.

4. McMonnies CW: Blink efficiency: a neglected area of ocular surface disease management? Invest Ophthalmol Vis Sci 2011, 52(7):4484.

5. Linton RG, Curnow DH, Riley WJ: The meibomian glands: an investigation into the secretion and some aspects of the physiology. Br J Ophthalmol 1961, 45(11):718-723.

6. Korb DR, Baron DF, Herman JP, Finnemore VM, Exford JM, Hermosa JL, Leahy CD, Glonek T, Greiner JV: Tear film lipid layer thickness as a function of blinking. Cornea 1994, 13(4):354-359.

7. McMonnies CW: Incomplete blinking: exposure keratopathy, lid wiper epitheliopathy, dry eye, refractive surgery, and dry contact lenses. Contact lens \& anterior eye: the journal of the British Contact Lens Association 2007, 30(1):37-51.

8. Tsubota K, Nakamori K: Dry eyes and video display terminals. N Engl J Med 1993, 328:584

9. Bleyen I, Hiemstra CA, Devogelaere T, van den Bosch WA, Wubbels RJ Paridaens DA: Not only hard contact lens wear but also soft contact lens wear may be associated with blepharoptosis. Can J Ophthalmol 2011, 46(4):333-336

10. Kojima T, Ibrahim OM, Wakamatsu T, Tsuyama A, Ogawa J, Matsumoto $Y$, Dogru M, Tsubota K: The impact of contact lens wear and visual display terminal work on ocular surface and tear functions in office workers. American journal of ophthalmology 2011, 152(6):933-940. e932.

11. Blackie CA, Korb DR, Knop E, Bedi R, Knop N, Holland EJ: Nonobvious obstructive meibomian gland dysfunction. Cornea 2010, 29(12):1333-1345.

doi:10.1186/1471-2415-13-34

Cite this article as: Kawashima and Tsubota: Tear lipid layer deficiency associated with incomplete blinking: A case report. BMC Ophthalmology 2013 13:34.

\section{Submit your next manuscript to BioMed Central and take full advantage of:}

- Convenient online submission

- Thorough peer review

- No space constraints or color figure charges

- Immediate publication on acceptance

- Inclusion in PubMed, CAS, Scopus and Google Scholar

- Research which is freely available for redistribution 